\title{
The Variation of Clothing Culture and the Transformation of Fashion Brands in Cross-cultural Communication
}

\author{
Yu Dai ${ }^{1, \text { a, }{ }^{*}, \dagger}$, Tianyi Zhou ${ }^{2, \text { b, }{ }^{*}, \dagger}$ \\ ${ }^{1}$ Basis International School Guangzhou, Guangzhou, China \\ ${ }^{2}$ Lake Forest Academy, Lake Forest, USA \\ ${ }^{*}$ Corresponding author. Email: ${ }^{a}$ Sissi4@foxmail.com, ${ }^{b}$ tianyi.zhou@students.lfanet.org \\ ${ }^{\dagger}$ These authors contributed equally.
}

\begin{abstract}
Variation and renewal are important characteristics of cross-cultural communication. With the popular hip-hop culture in China nowadays, this paper focuses on the Hoodie culture in hip-hop cultural symbols, and makes a preliminary investigation based on questionnaire survey and sample interview. The article holds that any kind of dress has its original function and culture, and even applies to special groups. In the process of cross-cultural communication, the cultural connotation of clothing is most prone to variation, simplification, or passive disappearance, which leads to the asymmetry between clothing and culture. This is not only related to the communication characteristics of intangible culture itself, but also closely related to the current new media environment. Meanwhile, the uncertainty of crosscultural communication also brings opportunities for the renewal of clothing brands, which can seize new market share through repositioning. This paper mainly analyzes the cross-cultural transformation of Champion as an example. These results provide new research cases for the cross-cultural communication of fashion brands and offer a guideline for the further study of the variation of clothing culture.
\end{abstract}

Keywords: Cross-cultural Communication, Hip-hop culture, Hoodie, Fashion Brands.

\section{INTRODUCTION}

Contemporarily, fast fashion had developed a lot and become common in people's daily life. Garment from different styles are gathered in one collection in store waiting for consumers, presenting purely with only one function: wearing. Garment that originated from a specific culture often has its corresponding functions and meanings, losing its original function and cultural connotation in the process of cross-cultural communication.

One of the noticeable trends in China comes from Hip-Hop culture. Because the Hip-Hop music are closely related to the culture behind, the image and wearing of Hip-Hop lover spread widely as the music spread. The Hip-Hop music style suddenly get popular in a few years, and Hip-Hop elements are naturally integrated into Chinese street fashion and became a main part of it simulataneously.
Based on the popularity of Chinese hip-hop culture, this paper focuses on the relationship between the popularity of hoodies and related brands and hip-hop culture itself. In terms of research methods, quantitative research and qualitative research are combined. There are two theoretical hypotheses. First, there is an asymmetry between the popularity of clothing and the cross-cultural communication of clothing culture. Second, popular culture and mass consumption provide an opportunity for the cross-cultural transformation of clothing brands.

\section{ASYMMETRY BETWEEN GARMENT AND CULTURE IN CROSS-CULTURAL COMMUNICATION}

\subsection{Popularization of Hip-Hop Music in China}

Various of physical things could be taken as a media to transfer information between expresser and audience. Each identical garment has its unique background and 
belongings to a culture, which gives garments the function of conduct meanings that owns by the garment or such want to express by the wearers [1]

Taking the Chinese TV show produced by iQiyi The Rap of China as an example. It was one of the most popular shows in 2015 that played the role of popularize the Hip-Hip music in China, serving as the media to spread the Hip-Hip music through reality show and stage. According to the questionnaire made by our group that targets the teenagers and young adults, which are, the main age group impacted by the Hip-hop boom started from 2015, a percentage of $68.99 \%$ of the sample have seen the show The Rap of China. More than two thirds of the sample was affected by the show, i.e., the show was a well known national degree show. However, only $60.75 \%$ of people choose they like the Hip-Hop culture, i.e., it also influences people who are not HipHop fans. The success of the show brought Hip-Hop music into a broad amount of people' $s$ eyes and pushing it enters the main stream of culture in China. The popularity and discussion of Hip-Hop reached a peak [2].

Hip-Hop culture spread with the music, and the clothing of the culture follows closely because the show as a media visualized figures and element of the HipHop culture, and the cloth is the most direct thing get memorized by the audience. Inside the show, MC Jin, one of the most popular Chinese rapper, created a character of Hip-Hop man. Hip-Hop man chooses a hoodie as its classical outfit, which also showed how this garment owned the meaning of Hip-Hop lover. However, the amount of people who constantly wearing the hoodie in their daily life is $13 \%$ percent more than the amount of people who love Hip-Hop music or culture in the questionnaire. Hoodie was created with the background of Hip-Hop culture.

\subsection{Hoodie culture as a trend}

In the sample of volunteer of the questionnaire, onefifth of the volunteers believed that they choose to wear the hoodie owing to the impact of Hip-Hop culture. Why do most of the people think a trend is exist, but at the same time believing they are not affected by the trend? The statistical data from the questionnaire may could answer this question.

According to the data, less than one-fifth of the people thought that they were influenced by the origin of the trend, The Rap Of China. Even though fewer than $20 \%$ of the volunteers thought that they were influenced by the show, four fifth of the volunteers were affected by the factor that was none direct but still originated from the impact of the show. They are not receiving direct information from the starting point of the trend, but they are impact by multiple additional product produced during the process of forming a trend. Human beings receive the matching and street fashion combine with the Hip-Hop element on social platforms, e.g., TikTok and Weibo. However, they did not realize that a subculture appears on a popular social media and facing the public is because of the trending letting it entering the mainstream of popular culture in a place.

It changed people's habit of wearing and simultaneously let them accept a subculture with the definition simplified by the media. Each one of the factor is supplement to each other and creating the trend with cooperation which they are pushing the process of one another [3]. Once the subculture becomes familiar, people start to assume following the trend is normal and not obtrusive so can avoiding problems caused by peoples' different opinions. The simplest way to keep peace is being "normal". More than half of the volunteers in the questionnaire are not considering the meaning behind the cloth they purchase and they "barely" read the garment with its meaning. The high school student Amanda stated in the interview that people choose garment based on understanding and hobbies. Most of them follow the trend blindly and don't even know the knowledge of fashion and dress matching, said by another respondents, Marilyn.

\subsection{Garments' meaning being simplified}

Subculture used to be uniting people with similar believe and perspective on viewing this world together in order to develop further idea or take on action to give them a solidified belonging [4]. The subculture define its own boarder line through competing against the popular culture and the mainstream trending [5]. The garment of a subculture group has the function of helping the members identify each others and give themselves identity [6]. Various of garment belongs to specific subculture is also necessary for the wearers to conduct to the audience not just the culture group they are belonging to, but also the characteristics they want to have through wearing this garment [7].

Garments that used to belongs to a subculture (e.g., hoodie) are losing its original meaning in this internet age. The fast developing online media are simplifying the wearing of subculture garment into a visual factor without any deeper meaning. That will create a information asymmetry between the people who belongs to the subculture group and someone falls in the popular culture but purchased the subculture garment, (e.g., the Hip-Hop representing garment, hoodie, wearing by so many consumers that not familiar with the Hip-Hop culture) [8]. One of the main causes is the lose of information during the process of information transferring. When the culture is represented by the garment, the culture is simplified into a few description words only focus on visual, or which described by some social media whose defined a culture with some most standing out and common characteristic, help creating a kind of stereotype. 


\subsection{How social media involve in this process of simplified}

It is necessary for social media to target a broad range of audience in order to gain larger influence on the internet. It results in that it is alternative for the social media to simplify information into short and nonacademic words to appeal to its audience mostly with no background knowledge or deeper understanding.

The culture is only understood and owned by a small community whose not expressing or trying to explain their belief too the public, what understand by the public with superficial description that only describe one perspective of the subculture, e.g., defining rock by rebellious and defining Hop-hop lover by gangsters [9]. It is often the simple direct version of culture get spread the most, especially on the platform focus on entertainment and trends. By the purpose of relax and entertain, people will pay less attention on the preciseness and deepness of the information. On Chinese social media, the most popular wide spread clothing trend originated from subculture are defined by a few represent words. For the same thing, the material side is always going to spread faster and easier comparing to its spiritual side, because the physical element is strait forward comparing to the ideal factor [10]. Comparing to the spiritual understanding, the purchase of the garment has no requirements after the subculture cloth are included into the broad market by commerce instead of completely self-remake.

The simplified version (mostly the visual version) of some subculture become a trend on the social media that influence the street fashion of people's life without carrying the culture behind it together.

\section{CROSS-CULTURAL TRANSFORMATION OF FASHION BRANDS: TAKE CHAMPION AS AN EXAMPLE}

There are countless popular fashion sports brands in mainland China. No matter those which are small or well-known, they are deeply welcomed by the public. Although some domestic sports brands have achieved excellent sales results, it is undeniable that most of the popular sports brands are originated from foreign countries.

Champion, as the sportswear brand is known, seems to be gaining traction in China in recent years. In a sign of the importance the brand places on the Chinese market, it has opened its first biggest store in Beijing's landmark fashion district of Sanlitun. In addition, there are countless famous domestic artists who have endorsed Champion. However, Champion, which originated in the United States, is not a trendy brand in the local market. It is often sold in large supermarket chains e.g., Walmart and Decathlon. The reasons attributed to its well-known features of sportswear brand when it came to China are discussed as following.

The development of the Asian market has brought benefits to the brand. In order to diversify its product line, Champion officially entered Japan in 1990, establishing a Japanese branch. In The Japanese market, its sports brand characteristics have been gradually diluted, to look more like a casual brand. Like other trendy brands in Japan, Champion began to move towards the street styles. Based on giving Champion Japan absolute autonomy, Japanese companies have had no problem designing clothes that fit local trends. Therefore, compared with the rugged American version, the materials of Japanese Champion are softer and more detailed. With this effective marketing strategy, Champion began to gain a foothold in the Asian market. In fact, co-branding and cooperation with major fashion brands also increased Champion's popularity in China [11]. In the co-branded pieces, Champion's once-austere ethos was buried by the other trendy brands. Many brands with large reputation like to raise the cost of their products by co-branding, carrying out the "hungermarketing” method. Supreme, for example, not only loves co-branding, but also the co-branded models are sold only for a limited time. Nevertheless, for the Champion' s co-branded model, it wasn't the limited time while it was sold that attracted the customers (doubling of its price). Basic Champion commodities typically cost between 200 and $650 \mathrm{RMB}$, which is between $\$ 30$ and $\$ 90$. However, Champions are priced between $\$ 300$ and $\$ 600$ in association with other brands, which is equivalent to 2,000 to 4,000 RMB. Such grandiose price increases are enough to justify the benefits of the Champion franchise. It is because of this joint signature again and again that Champion has won the favour and appreciation of many young fans. Clever marketing has helped Champion expand its presence in Asia, from being a niche sportswear brand to what people call a "fashion brand." Perhaps, in this era of rapid update frequency, only by constantly innovating and constantly creating topics can brands maintain stable sales and exposure rate.

The diverse success of the brand culture and product line has enabled Champion to present and leverage its strengths in the US, Japan, and Europe in the meantime. In USA, Champion styles are straight-forward and comfortable-based. In Japan, the styles directly follow the fashion trends among social formats. In Europe, Champion design their clothes with great sense of fashion and often cooperate with high-end designers and brands. Many people would then doubt on the distinction between the styles.

In fact, champion's high sales in recent years attest to their unique marketing approach. By giving the authority to producers in other countries so that they 
could alter the design of the clothing styles, the company created a rich production line, as well as an expanded range of customers. As each country has its own unique dressing habits and fashion vision, uniform clothing materials and designs will not achieve high sales in each country. Therefore, in order to match the clothing habits of the three countries, Champion offered the opportunity for the countries to change and redesign the products based on their own fashion visions. Champion designs originated from USA mainly focused on comfort and air permeability since people there would most likely wear this brand while exercising. Based on how people in USA like to wear, Champion designed the products with strong personality and free styles, in order to achieve high sales. Champion was developed in 1934 and up to now, it is still the classic Reverse Weave and BASIC series, as well as all MADE IN USA including fabric, thread and sewing, emphasizing durability and comfort. Since the 1980s, Champion came to Japan and produced several product series. ACTION STYLE has provided champions for professional sports, including the NBA, with a strong focus on professional sportswear. ACTION STYLE is a series that combines the functions of sportswear with street tailoring elements. CAMPUS, as the name suggests, is inspired by American campus wears, with more colorful colors and patterns, suitable for everyday wear. The WOMEN's collection includes leopard prints, colors, contrasting colors, loose one-pieces and the very popular wide trousers of these two seasons. From the fashion town of Europe line, the website layout appears more relaxed. The European production line features the fusion of fashion and sports. The PREMIUM series is based on the manufacture and concept of Reverse Weave, including Rick Owens, Cloth surgeon, the latest Chiara Ferragni, and Craig Green. Champion designs, regardless of which country, contain a unique exotic style and specific brand design concepts.

However, few people are aware of the brand's designs in different countries. Most people buy Champions for the outward appearance of the clothes rather than the origin and design concepts. According to the findings based on interviews, when buying clothes, three out of every four people don't go into the depth of the origins and non-general knowledge of brands. Therefore, the impact of clothing brands on customers is mainly in the appearance rather than the internal.

\section{CONCLUSION}

In summary, this paper mainly analyzes the fashion phenomenon in the process of Hip-hop music popularity and can preliminarily find the asymmetry between clothing and culture in the process of cross-cultural communication. Garments are born behind different cultural background and convey different meanings. However, the competitions between main stream popular culture and subculture are changing this. The subculture has been identified by a simple words by media people in popular culture, e.g., teenage rebellion or hatred of capitalism. On the one hand, this simplified version of subculture meaning can be more easily understood by common people, and the garment of the subculture spread as the subculture become more well known. On the other hand, the simplified version of the subculture makes the complex meaning and background behind it start to decompose. Eventually, the capitalist can subsume the subculture by letting common people identify them using the simplified meaning and direct visual expression.

During this process, the meaning of the garment start to become less important. It loses the function of express the subculture the wearer was in. Instead, it flows into the main stream fashion and start mass production, which makes it an ordinary fashion items that people can reach in the market without being in the community that the garment was originated. If we take garment as a media, we will realize that it does not conduct information like songs or articles with words. Even though some of the garment will have few words printed on it to represent it' $s$ meaning behind, most of them are convey information by indirect visual. Besides, it requires background knowledge and understanding of the culture behind in order to realize that. Most of the common people do not have the ability to identify the culture, and the garment do not have any requirement to the buyer. Therefore, the garment is successfully incorporated into the pop culture during this process.

Moreover, this asymmetry also brings opportunities for the transformation of fashion brands. In addition to the original function and meaning of clothing, we should also see the cross-cultural acceptance and adaptation of clothing. The process of cross-cultural communication and localization of clothing brand will help the brand find a new position and get a second life. Thus, paying attention to the cross-cultural communication and acceptance of clothing brands in the new media era will be a more challenging topic. Moreover, it is also the content that this paper needs to further explore in the future.

\section{REFERENCES}

[1] Gibson R., The Memory of Clothes, SensePublishers, 2015.

[2] Chen Zhihua, Influence of hip hop culture on current social popularity in China, Art review, 2017, 15, pp.129-130.

[3] Badaoui K, Lebrun A M, Bouchet P., Clothing Style, Music, and Media Influences on Adolescents' Brand Consumption Behavior, 
Psychology \& Marketing, 2012, 29(8). DOI : 10.1002/mar.20544

[4] Simon, D., The Function of Subculture, in The Cultural Studies Reader(2 ed.). New York: Routledge, 1999, pp. 441-450.

[5] Dick Hebdige, Subculture: the meaning of style, Peking University Press, 2009.

[6] Fathallah, J. M., Emo: how fans defined a subculture, University of Iowa Press, 2020.

[7] Liu Liping, The influence of youth subculture on clothing style, Popular literature and art, 2011, 7, pp. 141 .

[8] Feinberg RA, Mataro L, Burroughs WJ. Clothing and Social Identity, Clothing and Textiles Research Journal, 1992, 11(1), pp.18-23. DOI : $10.1177 / 0887302 X 9201100103$

[9] Myles Ethan Lascity, Communicating Fashion: Clothing, Culture, and Media, 2021. DOI:10.5040/9781350112278

[10] Richard A. Lambert, Christian Leuz, Robert E. Verrecchia, Information Asymmetry, Information Precision, and the Cost of Capital, Review of Finance, 2012, 6(1), pp.1-29. DOI:10.1093/rof/rfr014

[11] Shen Shuaibo, Why can champion, a century old brand, always come back from the dead, Sales and marketing, 2020, 7, pp.88-90. 